\title{
The activity of SnRK1 is increased in Phaseolus vulgaris seeds in response to a reduced nutrient supply
}

\section{Patricia Coello and Eleazar Martínez-Barajas*}

Departamento de Bioquímica, Facultad de Química, Universidad Nacional Autónoma de México, Ciudad de México, México

\section{Edited by:}

Matthew Paul, Rothamsted Research, UK

\section{Reviewed by:}

Frederik Börnke, Leibniz-Institute for Vegetable and Ornamental Crops,

Germany

Pierre Crozet, Fundação Calouste Gulbenkian - Instituto Gulbenkian de Ciência, Portugal

\section{${ }^{*}$ Correspondence:}

Eleazar Martínez-Barajas,

Departamento de Bioquímica, Facultad de Química, Universidad Nacional Autónoma de México, Ciudad de México, D.F. 04510, México e-mail:emtz@unam.mx

Phaseolus vulgaris seeds can grow and develop at the expense of the pod reserves after the fruits have been removed from the plant (Fountain etal., 1989). Because this process involves sensing the reduction of nutrients and the remobilisation of pod reserves, we investigated the effect on sucrose non-fermenting related kinase 1 (SnRK1) activity during this process. Bean fruits removed from the plant at 20 days after flowering (DAF) demonstrated active remobilisation of nutrients from the pod to the seeds. After 5 days, the pod dry weight was reduced by $50 \%$. The process was characterized by a rapid degradation of starch, with the greatest decrease observed on day 1 after the fruits were removed. The pod nutrients were insufficient for the needs of all the seeds, and only some seeds continued their development. Those seeds exhibited a transient reduction in sucrose levels on day 1 after the fruits were removed. However, the normal level of sucrose was recovered, and the rate of starch synthesis was identical to that of a seed developed under normal conditions. Removing the fruits from the plant had no effect on the activity of SnRK1 in the pods, whereas in the seeds, the activity was increased by $35 \%$. Simultaneously, a large reduction in seed sucrose levels was observed. The increase in SnRK1 activity was observed in both the cotyledon and embryo axes, but it was higher in the cotyledon. At 20$25 \mathrm{DAF}$, cotyledons actively accumulate storage materials. It is possible that the increase in SnRK1 activity observed in seeds developed in fruits that have been removed from the plant is part of the mechanism required for nutrient remobilisation under conditions of stress.

\section{Keywords: nutrient remobilisation, SnRK1, bean seed development}

\section{INTRODUCTION}

Seed development is a complex and highly resource-demanding process that requires large amounts of $\mathrm{C}$ and $\mathrm{N}$. Because of structural restrictions, legume embryos grow in an environment in which $\mathrm{O}_{2}$ represents only $0.4 \%$ of the atmospheric concentration, resulting in low ATP levels (Rolletschek et al., 2003). The adaptations of becoming green and photosynthetically active provide the $\mathrm{O}_{2}$ and energy required to increase biosynthetic fluxes. Early in development (pre-storage phase), embryos contain high levels of glucose (Weber et al., 1995). Later, sucrose becomes more abundant, and the switch from hexoses to sucrose is accompanied by cell differentiation and the synthesis of storage products (Borisjuk et al., 1995). In cotyledons of Vicia faba, high glucose concentrations are found in non-differentiated regions, and glucose concentrations are particularly low in mature starch-accumulating regions (Borisjuk et al., 1998). By contrast, starch-accumulating cells contain the highest sucrose concentrations (Borisjuk et al., 2002). ATP distribution is also important in regulating the accumulation of storage products. In $V$. faba cotyledons, protein accumulation occurs in the foremost regions, where ATP is more readily available, and starch synthesis is more active in the internal sections, where ATP levels are lower (Borisjuk et al., 2003). Sucrose non-fermenting related kinase 1 (SnRK1) is also a modulator of abscisic acid (ABA) functions, linking nutrient and/or energy state to ABA-regulated responses, and reduction in SnRK1 activity may cause either loss of ABA function and/or disconnection between metabolic signals and ABA, resulting in the prolonged expression of genes related to cell proliferation (Radchuk et al., 2006).

Variations in environmental factors (drought, high temperature, disease caused by pathogens, etc.) affect photosynthetic activity and may produce a significant reduction in the supply of nutrients required for seed development. Plants use different strategies to cope with conditions of stress, including nutrient remobilisation (Yang et al., 2001a). This process is normally associated with leaf senescence, where most of the available nutrients are transported to developing seeds (Yang et al., 2001b), but materials accumulated in stems and pods are also important for seed development (Schiltz et al., 2005). Seeds of Phaseolus vulgaris can continue their development at the expense of pod reserves when the fruits are removed from the plant at 15-25 days after flowering (DAF; Fountain et al., 1989). SnRK1 has been identified as an important component in the mechanism that allows plants to respond to C and energy deficiencies (Schluepmann et al., 2012). SnRK1 kinases function as heterotrimeric complexes composed of one catalytic subunit $(\alpha)$ and two regulatory subunits $(\beta-$ and $\gamma$-type subunits; Polge and Thomas, 2007). These kinases can phosphorylate and inactivate important enzymes, such as 3-hydroxy-3-methylglutaryl-coenzyme A reductase (HMG-CoA) reductase, sucrose phosphate synthase (SPS), and nitrate reductase 
(NR; Sugden et al., 1999). SnRK1 also phosphorylates trehalose phosphate synthase (TPS5; Harthill et al., 2006), fructose-6phosphate, 2-kinase/fructose-2,6-bisphosphatase (F2KP; Kulma et al., 2004) and non-phosphorylating glyceraldehyde 3-P dehydrogenase (Piattoni et al., 2011) and promote their association to 14-3-3 proteins. SnRK1 kinase activity is also required for the redox regulation of ADP glucose PPase (Tiessen et al., 2003). In pea cotyledons, SnRK1 coordinates and adjusts the physiological and metabolic demands of growth (Radchuk et al., 2010), and by mediating transcriptional reprograming in the cells, SnRK1 (AKIN10) also helps plants to survive adverse-energy depleting conditions (Baena-González et al., 2007). SnRK1 activity is under complex regulation, it increases in response to the phosphorylation of the catalytic subunit mediated for GRIK kinases (Shen et al., 2009) and is inhibited by trehalose 6-P (T6P), glucose 6-P, and glucose 1-P (Toroser et al., 2000; Zhang et al., 2009; Nunes et al., 2013b). T6P inhibition of SnRK1 is important in young tissue, and the dissociation constant $\left(\mathrm{K}_{\mathrm{i}}\right)$ for the SnRK1-T6P complex is calculated to be closer to 4 ( $\mu \mathrm{M}$; Nunes et al., 2013a). In this context, the main objective of this work is to investigate how SnRK1 activity is affected by the reduction in nutrient supply when bean fruits are removed from the plant.

\section{MATERIALS AND METHODS PLANT MATERIAL}

Bean seeds ( $P$. vulgaris $\mathrm{cv}$ V8025) were grown in a greenhouse at $25^{\circ} \mathrm{C}$ under a $14 \mathrm{~h}$ natural light/10 h dark regime in $3 \mathrm{~L}$ plastic pots with agrolite. They were irrigated daily with $150 \mathrm{~mL}$ Hoagland solution (Jones, 1982). Flowers were tagged at anthesis, and fruits were removed from the plant at $20 \mathrm{DAF}$ and incubated at $25^{\circ} \mathrm{C}$ in darkness. In fruits removed from the plant only seeds that were able to continuing their development were analysed.

\section{SUGAR DETERMINATION}

Pod and seed samples (200 mg) were homogenized in $3 \mathrm{~mL} \mathrm{80 \%}$ ethanol and extracted twice at $80^{\circ} \mathrm{C}$ for $15 \mathrm{~min}$. The soluble fraction was used to determine glucose, fructose, and sucrose. Starch was measured from the insoluble pellet using procedures previously reported (Bernal et al., 2005). Two fruits from three different plants were analyzed.

\section{PREPARATION OF PLANT EXTRACTS}

Plant material was frozen with liquid nitrogen and soluble protein was extracted at $4^{\circ} \mathrm{C}$ in homogenisation buffer containing $100 \mathrm{mM}$ Tricine- $\mathrm{NaOH}$ (pH 8.0), $5 \mathrm{mM}$ DTT, $0.5 \mathrm{mM}$ EGTA, $0.5 \mathrm{mM}$ EDTA, $10 \%$ glycerol, $0.02 \%$ Brij 35 and $1 \mathrm{mM}$ benzamidine. Prior to the homogenisation $1 \mathrm{mM}$ PMSF, $1 \mathrm{X}$ protease inhibitor cocktail (Sigma, Mexico), phosphatase inhibitors ( $5 \mathrm{mM}$ sodium fluoride, $2.5 \mathrm{mM} \beta$-glycerophosphate and $0.2 \mathrm{mM}$ sodium orthovanadate) and insoluble polyvinylpyrrolidone $(2 \% \mathrm{w} / \mathrm{v})$ were added. The homogenate was transferred to microfuge tubes, and insoluble material was removed by centrifugation $(13,000 \times g)$ at $4^{\circ} \mathrm{C}$ for $20 \mathrm{~min}$. The supernatant was desalted using an NAP-5 column (GE Healthcare) that was previously equilibrated with homogenisation buffer. Protein content was determined using Bradford reagent
(Sigma, Mexico), and the desalted material was used for the SDSPAGE (Laemmli, 1970). Proteins were visualized by staining with coomassie blue. Specific antibodies for the SnRK1 catalytic subunit were used for western-blot according to previously reported procedures (Fragoso et al., 2009). The phosphorylation of the catalytic subunit was evaluated with with an anti-phospho-AMPK $\alpha$ (T172) antibody (Cell Signaling). Densitometric analysis was performed using Image Lab software (Bio-Rad), and the blot signal was normalized by the amount of protein detected by coomassie blue staining.

\section{SnRK1 ASSAY}

The SnRK1 activity was assayed following a procedure previously reported (Zhang et al., 2009) in $25 \mu \mathrm{l}$ in microtiter plate wells at $30^{\circ} \mathrm{C}$. Assay medium was $40 \mathrm{mM}$ Hepes- $\mathrm{NaOH}, \mathrm{pH} 7.5,5 \mathrm{mM}$ $\mathrm{MgCl}_{2}, 200 \mu \mathrm{M}$ ATP containing $0.337 \mu \mathrm{Ci}\left[\gamma^{33} \mathrm{P}\right] \mathrm{ATP}$ (Perkin Elmer), $200 \mu \mathrm{M}$ AMARA peptide (AMARAASAAALARRR), $5 \mathrm{mM}$ DTT, 1X protease inhibitor cocktail (Sigma, Mexico) and phosphatase inhibitors ( $5 \mathrm{mM}$ sodium fluoride, $2.5 \mathrm{mM} \beta$ glycerophosphate and $0.2 \mathrm{mM}$ sodium orthovanadate). Assays were started with extract ( $5 \mu \mathrm{g}$ protein) and after $6 \mathrm{~min}, 15 \mu \mathrm{l}$ was transferred to $4 \mathrm{~cm}^{2}$ Whatman P81 phosphocellulose paper, immediately immersed in $1 \%$ phosphoric acid, then washed with three $800 \mathrm{ml}$ volumes of $1 \%$ phosphoric acid, immersed in acetone, dried, and transferred to liquid scintillation vials.

\section{RESULTS}

By 20-25 DAF, pods have reached their final size (Fountain et al., 1989), and fruit growth is mainly associated with the active accumulation of storage materials in seeds (Figure 1A). In fruits removed from the plant at $20 \mathrm{DAF}$, seeds can growth at the expense of the nutrients provided for the pod. In the 5 day period after the fruits were detached, the pods lost $50 \%$ of their dry weight, whereas a significant dry weight increase was observed in the seeds (Figure 1A). However, the material transported from the pod is not sufficient to fully cover the needs of the seeds. Figure $1 \mathbf{B}$ shows that after 5 days, only some seeds from the removed fruit were able to continue development, and a large dispersion in the size of individual seeds is observed (Figure 1C). Bean pods have a significant amount of starch, and approximately one third of it is normally degraded in the period from 20 to 25 DAF. In detached fruits, the process was accelerated, and two-thirds of the starch was hydrolysed during the first day after fruit removal (Figure 2). The levels of glucose, fructose and sucrose remained almost constant, and no changes were observed between the pods of fruits developed in the plant and the pods of fruits that were removed (Figure 2). Under normal conditions, sucrose tends to be reduced as seed matures. However, in the seeds of fruits that were removed from the plant, an important reduction was observed at day 1. Sucrose levels recovered gradually, and 3 days after the fruits were removed, the levels were identical to those in seeds developed under normal conditions (Figure 3). In seeds that were able to continue developing in removed fruits, the rate of starch accumulation decreased during the first 3 days and then returned to values similar to those observed in seeds developed under normal conditions (Figure 3). SnRK1 activity in pods showed a tendency to decrease from 20 to $25 \mathrm{DAF}$, and a similar response was observed in fruits removed 
A
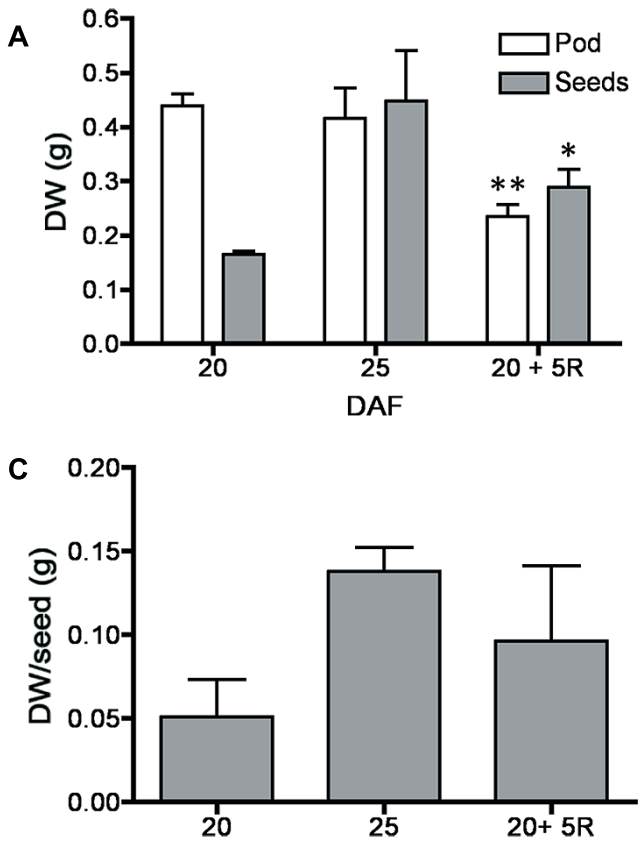

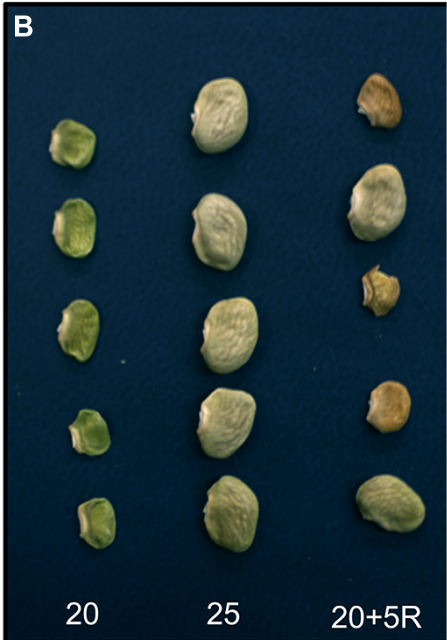

in a large variation in individual seed dry weight (C). Bars represent an average of the analysis of 25 fruits $\pm \mathrm{SD}, *$ and ${ }^{*}$ denote significant differences at $p<0.05$ and 0.01 by ANOVA, respectively. Experiments were replicated three times with identical results. from the plant at 20 DAF 5 days later $(20+5 R)$ there was a $50 \%$ reduction in pod dry weight and a significant increment in dry weight of seeds (A). Only some seeds in the removed pods continued their development (B), resulting
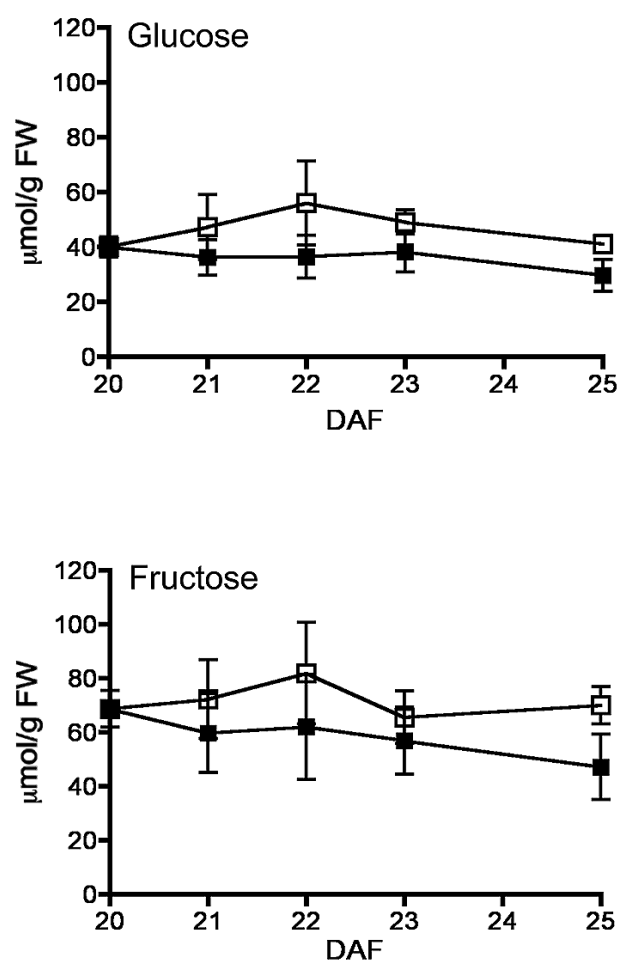

FIGURE 2 | Effect of fruit removal on pod glucose, fructose, starch, and sucrose levels. Bean fruits were removed from the plant at $20 \mathrm{DAF}(\square)$, and carbohydrate levels were compared to fruits developed attached to the plant
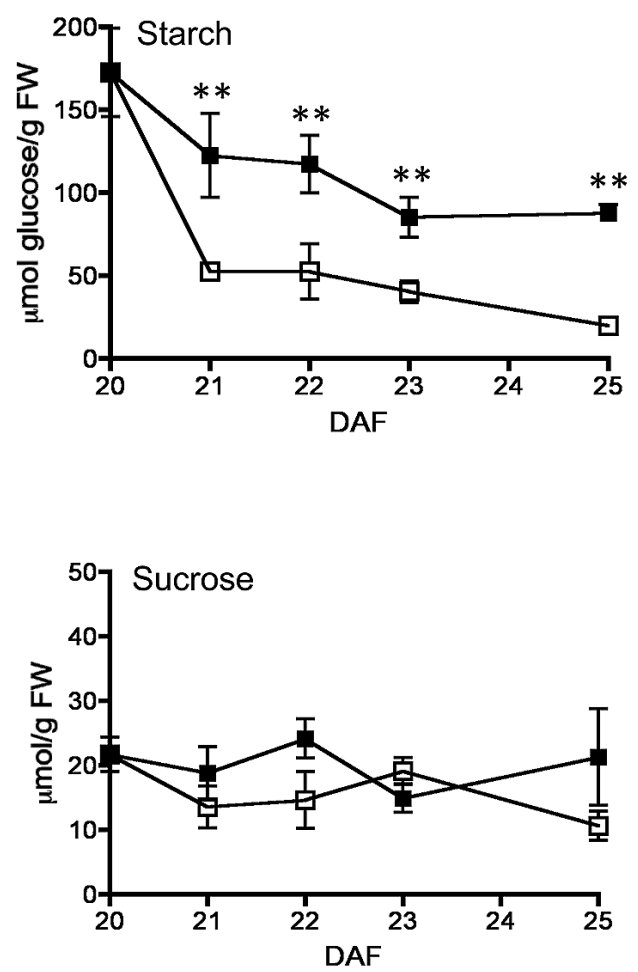

Data points represent the average of three fruits from different plants $\pm \mathrm{SD},{ }^{*} p<0.01$ by ANOVA. Experiments were replicated three times with identical results. 


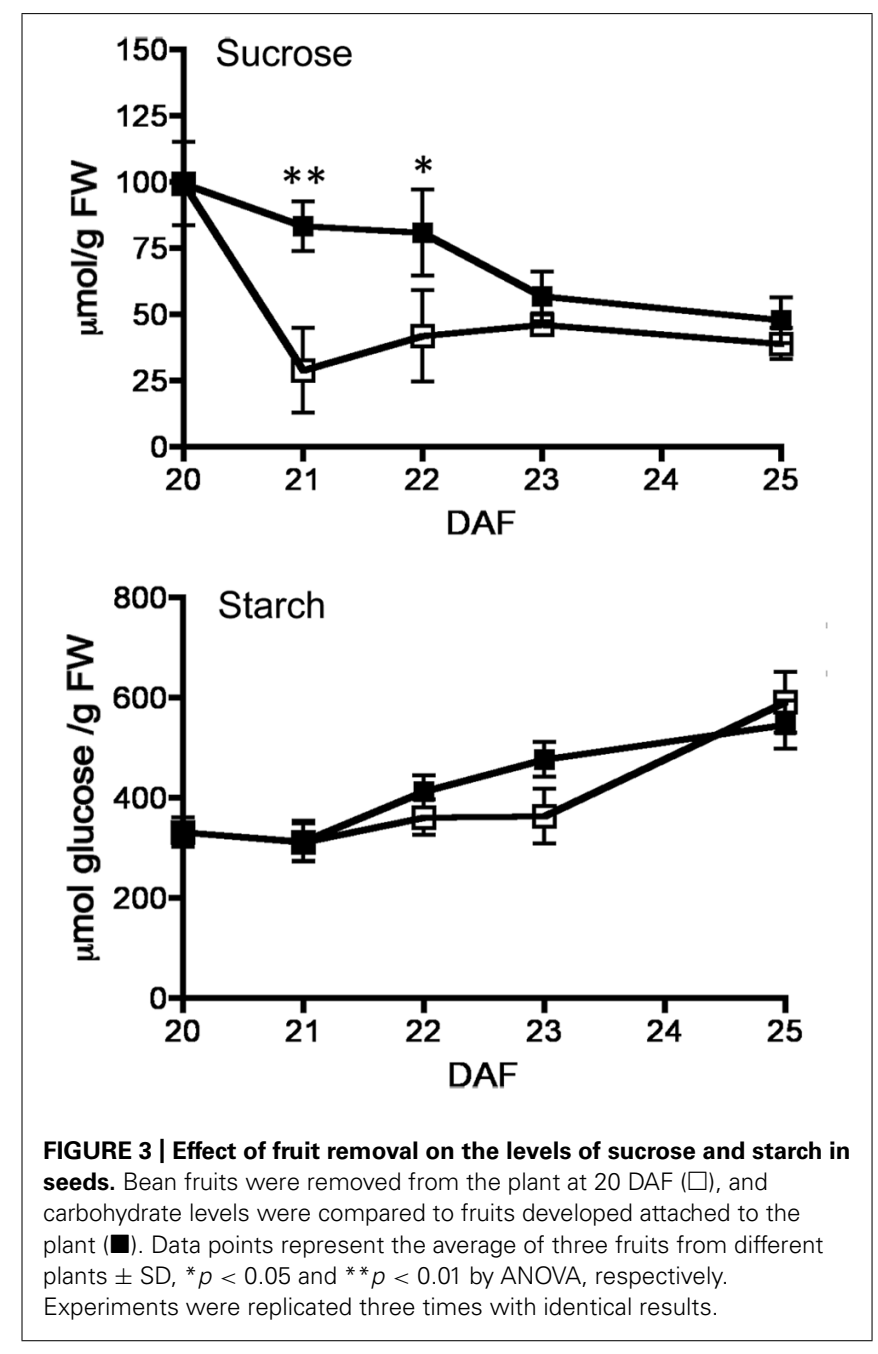

from the plant (Figure 4A). In seeds, fruit removal resulted in a $35 \%$ increase in SnRK1 activity at day 1 (Figure 4B). The increase in SnRK1 activity coincided with the largest reduction in sucrose (Figure 3). The abundance of total and phosphorylated SnRK1 catalytic subunit was also analyzed. In normally developed seeds, SnRK1 catalytic subunit showed a tendency to decrease after 20 DAF, while in the seeds developed in removed fruits the process is slower (Figure 4D and Supplementary Figure 1). In the period from 20 to 25 DAF the phosphorylation of the catalytic subunit is low in seeds developed normally, but it increased at 1-3 days after the fruits were removed from the plant (Figure $4 \mathrm{E}$ and Supplementary Figure 1). SnRK1 activity was also measured in cotyledons and embryo axes of seeds of $21 \mathrm{DAF}$ and in seeds of 20 DAF fruits the day after removal from the plant. In both cases, removing the fruits from the plant increased the activity with a larger increase observed for cotyledons (Figure 5A). The western-blot analysis shows that the increment in SnRK1 activity was not associated with changes in the abundance of catalytic subunit (Figure 5C). However, large increment in the phosphorylation of the catalytic subunit was observed in cotyledon extracts, while in embryo axe the phosphorylation of the catalytic subunit is reduced (Figure 5D).

\section{DISCUSSION}

At 20 DAF, bean pods have completed their development, and the period from 20 to 25 DAF is characterized by the active growth of the seeds (Figure 1A). Later in development, pods can transfer some materials to support seed needs (Schiltz et al., 2005), however, according to previous research (Fountain et al., 1989), when bean fruits are removed from the plant within this period, the pod is converted to provide nutrients for seed development. The present study found that this process is characterized by the rapid reduction of starch, and almost two-thirds of the initially present in pod tissue was degraded during the first day after the fruit was detached (Figure 2). In addition to starch, the degradation of other materials may also contribute to seed development. Bean pods also contain galactose-rich pectin polymers that are degraded at the maturation of the fruits (Stolle-Smits et al., 1999), and proteins stored in soybean pods make a significant contribution to the pool of nutrients mobilized for developing seeds (Staswick, 1989). It has been estimated that in Pisum sativum, the $\mathrm{N}$ remobilised from the pods contributes to $20 \%$ of the seed $\mathrm{N}$ (Schiltz et al., 2005). By removing the fruits from the plant, both pod and seeds were subjected to a severe nutritional deficiency. This nutrient loss was partially compensated by the acceleration of starch degradation in the pods (Figure 2). It is also possible that some seeds are sacrificed to increase the probability to develop some viable seeds (Figure 1B). However, the reserves transferred from the pods are insufficient to fully supply the needs of all seeds (Figure 1), and a large reduction in sucrose was observed at 1 day after the fruits were detached. Sucrose gradually increased, and after 3 days returned to those levels observed in normally developing seeds, when the rate of starch accumulation was also recovered (Figure 3). SnRK1 controls the early steps of cotyledon growth and differentiation and is required to transmit a nutrient-derived signal that stimulates the gene expression involved in nutrient partitioning (Radchuk et al., 2010). SnRK1 also mediates low-energy stress responses (BaenaGonzález and Sheen, 2008). Its activity in the pods was not affected by removing the fruits from the plant (Figure 4A). However, in seeds that were able to develop in detached fruits a $35 \%$ increase was observed 1 day after its removal (Figure 4B). It coincided with the largest reduction in sucrose levels detected in the seeds, and the difference disappeared as soon as the sucrose levels were restored (Figures 3 and 4B). Sugar starvation and ABA transcriptionally activates SnRK1 (Radchuk et al., 2010). It might contribute to the higher level of catalytic subunit observed in seeds of detached fruits (Figure 4D and Supplementary Figure 1). However, the increment in SnRK1 activity observed in those seeds was associated with larger proportion of the catalytic subunit that appears phosphorylated (Figure 4E and Supplementary Figure 1).

In bean seeds, SnRK1 activity reaches its highest point around 20 DAF (Coello and Martínez-Barajas, 2014), and it peaks at 18 DAF in pea seeds (Radchuk et al., 2010). Eventhoug SnRK1 activity is close to the highest value that can be reached in bean seed development, sugar deprivation can produce further increments (Figure 4B). It has been estimated that in vivo, up to $80 \%$ or more of SnRK1 activity is inhibited by T6P (Nunes et al., 2013a). T6P concentration is highly variable, depending on tissue type and environmental conditions (Martinez-Barajas et al., 2011; Nunes et al., 2013a), and generally, T6P levels correlate well with levels 

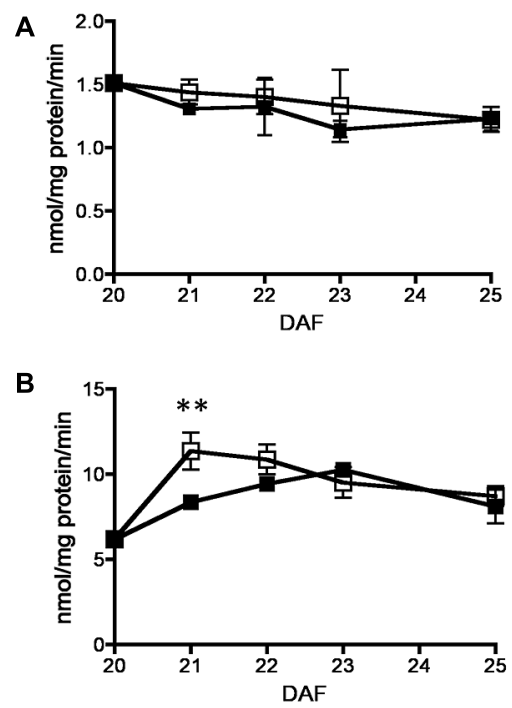

FIGURE 4 | Effect of fruit removal on the activity of SnRK1 in pods (A) and seeds (B) from fruits removed from the plant at 20 DAF ( $\square$ ) and developed normally ( $\square$ ). Data points represent the average of three fruits from different plants $\pm \mathrm{SD},{ }^{*} p<0.01$ by ANOVA. SDS-PAGE stained with coomassie blue of seed proteins

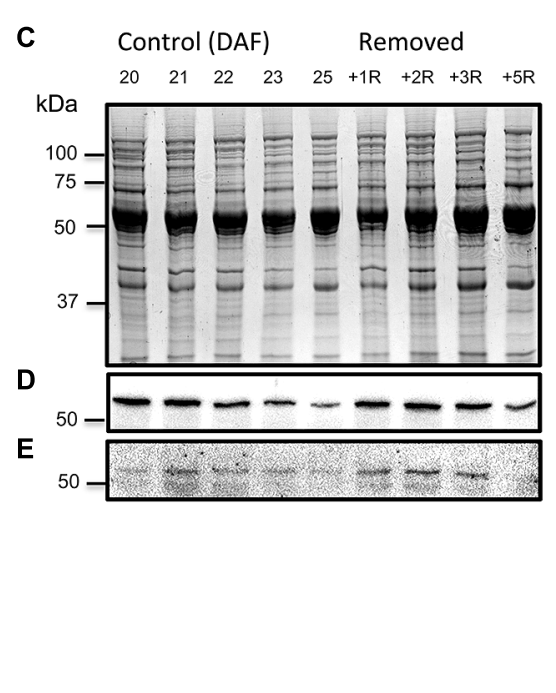

from fruits of 20 to 25 DAF developed under normal conditions (control) or in fruits removed at 20 DAF (removed) and analyzed 1-5 days after (C). Western-blot for total (D) and phosphorylated (E) SnRK1 catalytic subunit. Experiments were repeated two times with identical results. of sucrose in plant tissues (Lunn et al., 2006; Martinez-Barajas et al., 2011; Wingler et al., 2012; Nunes et al., 2013a). It has been suggested that the inhibition of SnRK1 activity by T6P allows the cells to initiate the anabolic processes required for growth. When carbon availability decreases, T6P is also reduced, and active SnRK1 participates in the processes required to make carbon available to sink cells into growth (Schluepmann et al., 2012).
The highest concentrations of T6P have been reported early in wheat seed development, in which SnRK1 activity is also high (Martinez-Barajas et al., 2011). There is no information available regarding T6P levels in $P$. vulgaris seeds. However, since we did not observed changes in sensitivity of SnRK1 activity to T6P in the seeds of detached fruits (data not shown), we cautiously speculate that a reduction in T6P when sucrose declines (Figure 3),
A

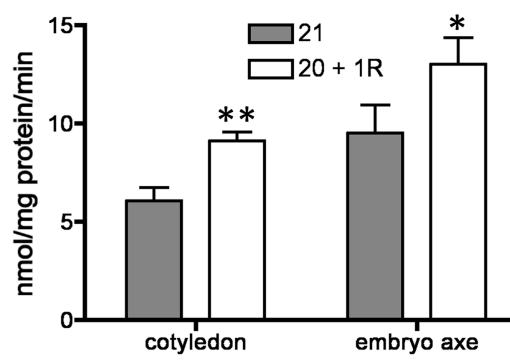

B

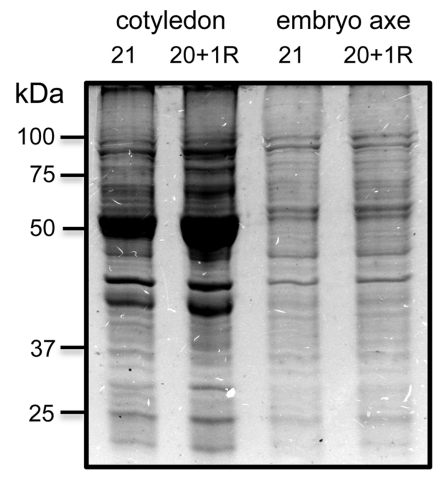

C

D
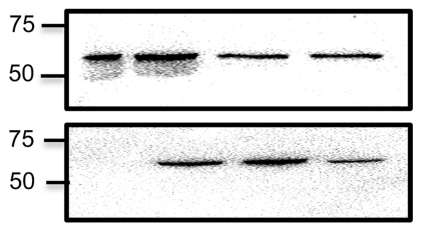

determinations $\pm \mathrm{SD},{ }^{*} p<0.05$ and ${ }^{* *} p<0.01$ by ANOVA, respectively (A). SDS-PAGE stained with coomassie blue (B) and western-blot for total (C) and phosphorylated (D) SnRK1 catalytic subunit. Experiments were repeated two times with identical results. 
will increase the relevance of SnRK1 activity to promote seed development under nutrient deficiency. The data presented here suggest that it is complemented by the changes in the phosphorylation status of the catalytic subunit (Figure $4 \mathrm{E}$ ). The regulation of the phosphorylation of the catalytic subunit could be important to promote differential responses in cotyledon and embryo axe to the nutrient deprivation. Finally, plants provide a number of nutrients to support seed development (sugars, amino acids, minerals, water, among others). On the other hand, SnRK1 is a modulator of ABA functions, linking nutrient and/or energy state to ABA-regulated responses (Finkelstein et al., 2002; Radchuk et al., 2006; Jossier et al., 2009; Rodrigues et al., 2013). It will be important to investigate how the individual nutrients and ABA contribute to the responses observed in seeds of detached fruits.

\section{AUTHOR CONTRIBUTIONS}

Conceived and designed the experiments Patricia Coello and Eleazar Martínez-Barajas. Performed the experiments Eleazar Martínez-Barajas. Analyzed the data Patricia Coello and Eleazar Martínez-Barajas. Wrote the paper Patricia Coello and Eleazar Martínez-Barajas.

\section{ACKNOWLEDGMENTS}

The skilful technical assistance provided by Alejandra Ávila and Laurel Fabila is deeply appreciated. We thank to Dr. Jorge AcostaGallegos (INIFAP) for providing bean seeds. This research was supported by DGAPA-UNAM (IN217811) and FQ-UNAM (PAIP 429014).

\section{SUPPLEMENTARY MATERIAL}

The Supplementary Material for this article can be found online at: http://www.frontiersin.org/Journal/10.3389/fpls.2014.00196/ abstract

\section{REFERENCES}

Baena-González, E., Rolland, F., Thecelein, J. M., and Sheen, J. (2007). A central integrator of transcription networks in plant stress and energy signalling. Nature 448, 938-942. doi: 10.1038/nature06069

Baena-González, E., and Sheen, J. (2008). Convergent energy and stress signalling. Trends Plant Sci. 13, 474-482. doi: 10.1016/j.tplants.2008.06.006

Bernal, L., Coello, P., and Martinez-Barajas, E. (2005). Possible role played by R1 protein in starch accumulation in bean (Phaseolus vulgaris) seedlings under phosphate deficiency. J. Plant Physiol. 162, 970-976. doi: 10.1016/j.jplph.2004.12.005

Borisjuk, L., Rolletschek, H., Walenta, S., Panitz, R., Wobus, U., and Weber, H. (2003). Energy status and its control on embryogenesis of legumes. ATP distribution withing Vicia faba embryos is developmentally regulated and correlated with photosynthetic capacity. Plant J. 36, 318-329. doi: 10.1046/j.1365313X.2003.01879.x

Borisjuk, L., Walenta, S., Roelletschek, H., Mueller-Klieser, W., Wobus, U., and Weber, H. (2002). Spatial analysis of plant development: sucrose imaging whiting Vicia faba cotyledons reveals specific development patterns. Plant J. 15, 583-591. doi: 10.1046/j.1365-313X.1998.00214.x

Borisjuk, L., Walenta, S., Weber, H., Mueller-Klieser, W., and Wobus, W. (1998). High-resolution histographical mapping of glucose concentrations in developing cotyledons of Vicia faba in relation to mitotic activity and storage process: glucose as a possible developmental trigger. Plant J. 15, 583-591. doi: 10.1046/j.1365313X.1998.00214.x

Borisjuk, L., Weber, H., Panitz, R., Manteuffel, R., and Wobus, U. (1995). Embryogenesis of Vicia faba L: histodiferentiation in relation to starch and storage protein synthesis. J. Plant Physiol. 147, 203-218. doi: 10.1016/S0176-1617(11)81507-5
Coello, P., and Martínez-Barajas, E. (2014). SnRK1 is differentially regulated in the cotyledon and embryo axe of bean (Phaseolus vulgaris L) seeds. Plant Physiol. Biochem. 80, 153-159. doi: 10.1016/j.plaphy.2014.03.033

Finkelstein, R. R., Gampala, S. S., and Rock, C. D. (2002). Abscisic acid signalling in seeds and seedlings. Plant Cell 14(Suppl.), S15-S45. doi: 10.1105/tpc.010441

Fountain, D. W., Outred, H. A., Holdsworth, J. M., and Thomas, R. G. (1989). Seed development in Phaseolus vulgaris L. cv Seminole: I. Developmental Independence of seed maturation. Plant Physiol. 89, 333-340. doi: 10.1104/pp.89.1.333

Fragoso, S., Espindola, L., Paez-Valencia, J., Gamboa, A., Camacho, Y., MartinezBarajas, E., et al. (2009). SnRK1 isoforms AKIN10 and AKIN11 are differentially regulated in Arabidopsis plants under phosphate starvation. Plant Physiol. 149, 1906-1916. doi: 10.1104/pp.108.133298

Harthill, J. E., Meek, S. E. M., Morrice, N., Peggie, M. W., Borch, J., Wong, B. H. C., et al. (2006). Phosphorylation and 14-3-3 binding of Arabidopsis trehalosephosphate synthase 5 in response to 2-deoxyglucose. Plant J. 47, 211-223. doi: 10.1111/j.1365-313X.2006.02780.x

Jones, J. B. (1982). Hydroponics: it history and use in plant nutrition studies. J. Plant Nutr. 5, 1003-1030. doi: 10.1080/01904168209363035

Jossier, M., Bouly, J.-P., Meimoun, P., Arjmand, A., Lessard, P., Hawley, S., et al. (2009). SnRK1 (SNF1-related kinase 1) has a central role in sugar and ABA signalling in Arabidopsis thaliana. Plant J. 59, 316-328. doi: 10.1111/j.1365313X.2009.03871.x

Kulma, A., Vikkadsen, D., Campbell, D. G., Meek, S. E. M., Harthill, J. E., Nielsen, T. H., et al. (2004). Phosphorylation and 14-3-3 binding of Arabidopsis 6-phosphofructo-2-kinase/fructose-2,6-bisphosphatase. Plant J. 37, 654-667. doi: 10.1111/j.1365-313X.2003.01992.x

Laemmli, U. K. (1970). Cleavage of structural proteins during the assembly of the head bacteriophage T4. Nature 227, 680-685. doi: 10.1038/227680a0

Lunn, J. E., Feil, R., Hendriks, J. H. M., Gibon, Y., Morcuende, R., Osuna, D., et al. (2006). Sugar-induced increases in trehalose 6-phosphate are correlated with redox activation of ADPglucose pyrophosphorylase and higher rates of starch in Arabidopsis thaliana. Biochem. J. 397, 139-148. doi: 10.1042/BJ20060083

Martinez-Barajas, E., Delatte, T., Schluepmann, H., de Jong, G. J., Somsen, G. W., Nunes, C., et al. (2011). Wheat grain development is characterized by remarkable trehalose 6-phosphate accumulation pregrain filling: tissue distribution and relationship to SNF1-related protein kinase 1 activity. Plant Physiol. 156, 373-381. doi: 10.1104/pp.111.174524

Nunes, C., O’Hara, L. E., Primavesi, L. F., Delatte, T. L., Schluepmann, H., Somsen, G. W., et al. (2013a). The trehalose 6-phosphate/SnRK1 signalling pathway primes growth recovery following relief of sink limitation. Plant Physiol. 162, 1720-1732. doi: 10.1104/pp.113.220657

Nunes, C., Primavesi, L. F., Patel, M. K., Martinez-Barajas, E., Powers, S. J., Sagar, R., et al. (2013b). Inhibition of SnRK1 by metabolites: tissue-dependent effects and cooperative inhibition by glucose 1-phosphate in combination with trehalose 6phosphate. Plant Physiol. Biochem. 63, 89-98. doi: 10.1016/j.plaphy.2012.11.011

Piattoni, C. V., Bustos, D. M., Guerreo, S. A., and Iglesias, A. A. (2011). Nonphosphorylating glyceraldehyde-3-phosphate dehydrogenase is phosphorylated in wheat endosperm at serine- 404 by SNF1-related protein kinase allosterically inhibited by ribose-5-phosphate. Plant Physiol. 156, 1337-1350. doi: 10.1104/pp.111.177261

Polge, C., and Thomas, M. (2007). SNF1/AMPK/SnRK1 kinases, global regulators at the heart of the energy control? Trends Plant Sci. 12, 20-28. doi: 10.1016/j.tplants.2006.11.005

Radchuk, R., Emery, R. J. N., Weier, D., Vigeolas, H., Geigenberger, P., Lunn, J. E., et al. (2010). Sucrose non-fermenting kinase 1 (SnRK1) coordinates metabolic and hormonal signals during pea cotyledon growth and differentiation. Plant J. 61, 324-338. doi: 10.1111/j.1365-313X.2009.04057.x

Radchuk, R., Radchuk, V., Weschke, W., Borisjuk, L., and Weber, L. (2006). Repressing the expression of the sucrose nonfermenting-1-related protein kinase gene in pea embryo causes pleiotropic defects of maturation similar to an abscisic acid insensitive phenotype. Plant Physiol. 140, 263-278. doi: 10.1104/pp.105. 071167

Rodrigues, A., Adamo, M., Crozet, P., Margalha, L., Confraria, A., Marthino, C., et al. (2013). ABI1 and PP2CA phosphatases are negative regulators of Snf1related protein kinase 1 signaling in Arabidopsis. Plant Cell 25, 3871-3884. doi: 10.1105/tpc.113.114066

Rolletschek, H., Weber, H., and Borijuk, L. (2003). Energy status and its control on embryogenesis of legumes. Embryo photosynthesis contributes to oxygen 
supply and is coupled to biosynthetic fluxes. Plant Physiol. 132, 1196-1206. doi: 10.1104/pp.102.017376

Schiltz, S., Munier-Jolain, N., Jeudy, C., Burstin, J., and Salon, C. (2005). Dynamics of exogenous nitrogen partitioning and nitrogen remobilization from vegetative organs in pea revealed by $15 \mathrm{~N}$ in vivo labelling throughout seed filling. Plant Physiol. 137, 1463-1473. doi: 10.1104/pp.104.056713

Schluepmann, H., Berke, L., and Sanchez-Perez, G. F. (2012). Metabolic control over growth: a case for trahalose-6-phosphate in plants. J. Exp. Bot. 63, 3379-3390. doi: $10.1093 / j x b / e r r 311$

Shen, W., Reyes, M. I., and Hanley-Bowdoin, L. (2009). Arabidopsis protein kinases GRIK1 and GRIK2 specifically activate SnRK1 by phosphorylating its activation loop. Plant Physiol. 150, 996-1005. doi: 10.1104/pp.108.132787

Staswick, P. E. (1989). Preferential loss of an abundant storage protein from soybean pods during seed development. Plant Physiol. 90, 1252-1255. doi: $10.1104 /$ pp. 90.4 .1252

Stolle-Smits, T., Beekhuizen, J. G., Kok, M. T. C., Pijnenburg, M., Recourt K., Derksen, J., et al. (1999). Changes in cell wall polysaccharides of green bean during development. Plant Physiol. 121, 363-372. doi: 10.1104/pp.121. 2.363

Sugden, C., Donaghy, P. G., Halford, N. G., and Hardie, D. G. (1999). Two SNF1related protein kinases from spinach leaf phosphorylate and inactivate 3-hydroxy3-methylglutaryl-coenzyme A reductase, nitrate reductase, and sucrose phosphate synthase. Plant Physiol. 120, 257-274. doi: 10.1104/pp.120.1.257

Tiessen, A., Preschaa, K., Branscheid, A., Palacios, N., McKibbin, R., Halford, N. G., et al. (2003). Evidence that SNF1-related kinase and hexokinase are involved in separated sugar-signalling pathways modulating post-translational redox activation of ADP-glucose pyrophosphorylase in potato tubers. Plant J. 35, 490-500. doi: 10.1046/j.1365-313X.2003.01823.x

Toroser, D., Plaut, Z., and Huber, S. C. (2000). Regulation of plant SNF1related protein kinase by glucose-6-phosphate. Plant Physiol. 123, 403-412. doi: 10.1104/pp.123.1.403

Weber, H., Borisjuk, L., Heim, L., Buchner, P., and Wobus, U. (1995). Seed-coat associated invertases of Fava bean control both unloading and storage functions: cloning of cDNAs and cell type-specific expression. Plant Cell 7, 1835-1846. doi: 10.1105/tpc.7.11.1835

Wingler, A., Delatte, T. L., O’Hara, L. E., Primavesi, L. F., Jhurreea, D., Paul, M. J., et al. (2012). Trehalose 6-phosphate is required for the onset of leaf senescence associated with high carbon availability. Plant Physiol. 158, 1241-1251. doi: 10.1104/pp.111.191908

Yang, J., Zhang, J., Wang, Z., and Zhu, Q. (2001a). Activities of starch hydrolytic enzymes and sucrose-phosphate synthase in the stems of rice subjected to water stress during grain filling. J. Exp. Bot. 52, 2169-2179.

Yang, J., Zhang, J., Wang, Z., Zhu, Q., and Liu, L. (2001b). Water deficit-induced senescence and its relationship to the remobilization of pre-stored carbon in wheat during grain filling. Agron. J. 93, 196-206. doi: 10.2134/agronj2001.931196x

Zhang, Y., Primavesi, L. F., Jhurreea, D., Andralojc, P. J., Mitchell, R. A., Powers, S. J., et al. (2009). Inhibition of SNF1-related protein kinase 1 activity and regulation of metabolic pathways by trehalose 6-phosphate. Plant Physiol. 149, 1860-1871. doi: $10.1104 /$ pp.108.133934

Conflict of Interest Statement: The authors declare that the research was conducted in the absence of any commercial or financial relationships that could be construed as a potential conflict of interest.

Received: 25 January 2014; accepted: 23 April 2014; published online: 16 May 2014 Citation: Coello P and Martinez-Barajas E (2014) The activity of SnRK1 is increased in Phaseolus vulgaris seeds in response to a reduced nutrient supply. Front. Plant Sci. 5:196. doi: 10.3389/fpls.2014.00196

This article was submitted to Plant Physiology, a section of the journal Frontiers in Plant Science.

Copyright (C) 2014 Coello and Martinez-Barajas. This is an open-access article distributed under the terms of the Creative Commons Attribution License (CC BY). The use, distribution or reproduction in other forums is permitted, provided the original author(s) or licensor are credited and that the original publication in this journal is cited, in accordance with accepted academic practice. No use, distribution or reproduction is permitted which does not comply with these terms. 